\title{
Jan van Eyck y España. Un viaje y una obra*
}

\author{
Bart FRANSEN \\ Institut du Patrimoine Royal, Bruxelles \\ fransenbart@kikipa.be
}

\begin{abstract}
RESUMEN
Jan van Eyck es sin duda el más célebre de todos los artistas flamencos del siglo XV. Su nombramiento en 1425 como pintor de corte de Felipe el Bueno hizo extender su fama rápidamente por toda Europa. Al servicio del duque realizó varios viajes, entre ellos uno a España y Portugal en 1428-1429. Las huellas que dejó Jan van Eyck en España han obsesionado a múltiples historiadores de arte. A pesar de las influencias eyckianas en varios pintores castellanos y aragoneses, sólo se conserva una tabla procedente del taller del maestro, destinada originariamente a España: la Fuente de la Vida, actualmente en el Museo del Prado. Esta tabla enigmática y magnífica es la primera que atestigua el enorme aprecio del arte de Van Eyck en España ya desde el siglo XV.
\end{abstract}

Palabras clave: Van Eyck, España, La Fuente de la Vida, Monasterio de El Parral.

\begin{abstract}
Jan van Eyck is undoubtedly the most famous of the Flemish artists of the fifteenth century. His appointment in 1425 as court painter to Philip the Good made his fame spread rapidly throughout Europe. By order of the duke he made several trips abroad, including one to Spain and Portugal in 1428-1429. The traces left by Jan van Eyck in Spain have haunted many art historians. Despite Eyckian influences in various Castilian and Aragonese painters, only one panel is conserved from the master's workshop that was specially made for Spain: The Fountain of Life, now in the Prado Museum. This enigmatic and magnificent painting is the first to witness the deep appreciation of the art of Van Eyck in Spain since the fifteenth century.
\end{abstract}

Keywords: Van Eyck, Spain, The Fountain of Life, Monastery of El Parral.

Cuando en mayo de 1425 Jan van Eyck fue nombrado pintor de corte por Felipe el Bueno (1396-1467) no sólo llevó a cabo pinturas para el duque sino también estuvo implicado en distintas misiones diplomáticas. Realizó así por orden del duque varios viajes lejanos y secretos que han mantenido intacta su aureola de misterio hasta el día de hoy. Tan sólo se conoce el destino de uno de estos viajes secretos: la Península Ibérica. Este viaje ha nutrido abundantemente la bibliografía sobre Jan van Eyck y España. A menudo ha sido sobrevalorado y relacionado con encargos españoles, con influencias españolas en la obra de Van Eyck y con influencias eyckianas en la obra de pintores españoles. En este debate ocupa un papel central la pintura La Fuente de

* Agradezco la ayuda de Till Borchert, Luc Dequeker y Felipe Pereda con quienes he podido intercambiar ideas y reflexiones sobre La Fuente de la Vida. También doy las gracias a Pilar Silva, a Carmen Garrido y su equipo del Gabinete Técnico del Museo del Prado por haberme facilitado información técnica y documentos fotográficos de la obra. Finalmente agradezco a la Fundación de los Amigos del Museo del Prado, el promotor inicial de esta investigación. 


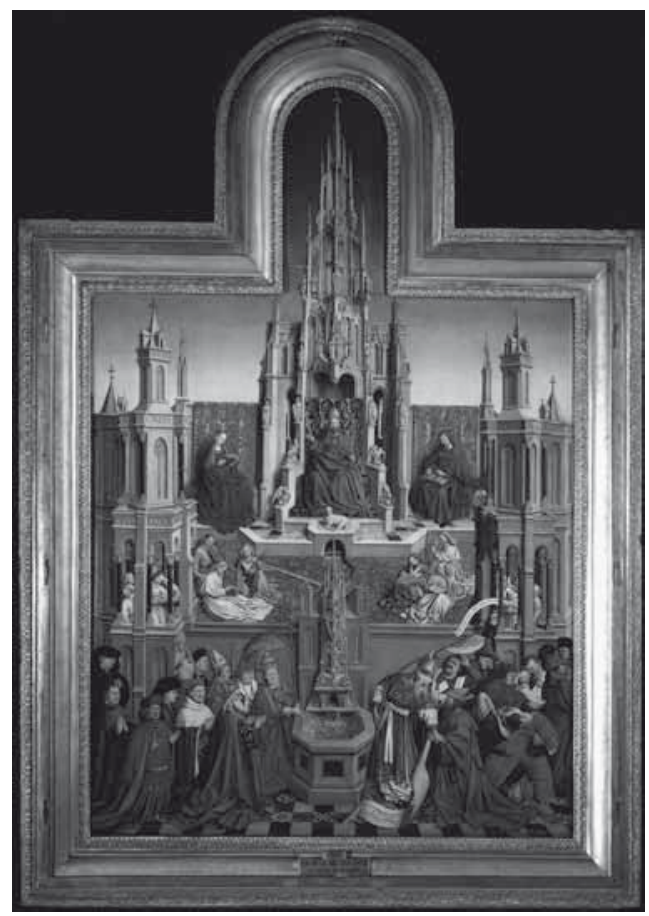

Fig. 1. Jan Van Eyck (taller), La Fuente de la Vida, h. 1435 (Museo del Prado, Madrid). la Vida (fig. 1), conservada en el Museo del Prado, sobre la que se han publicado nuevas teorías en los últimos años. En este artículo quiero por un lado resumir el relato del viaje de Jan van Eyck, ya publicado $^{1}$, y por otro comentar y situar las recientes teorías sobre La Fuente de la Vida. Para ello me baso en el panorama de las múltiples teorías tal y como lo he publicado en el 2009.

\section{Un viaje}

En 1428 Felipe el Bueno envió una representación al Rey Juan I de Portugal (1359-1433) con el objetivo de solicitar la mano de su hija mayor Isabel (13971471). Aunque esta misión se menciona en las cuentas de la corte como un viaje secreto, poseemos bastante información sobre esta aventura gracias a una detallada crónica del viaje escrita en francés y conservada en los Archivos de Estado en Bélgica ${ }^{2}$.

La misión estaba liderada por el caballero Jean de Roubaix, consejero y primer chambelán del duque. Los otros miembros de la delegación eran el caballero

1 Este artículo es en gran parte una reedición aumentada de B. FRANSEN, "Jan van Eyck, "el gran pintor del ilustre duque de Borgoña'. Su viaje a la Península y la Fuente de la Vida”, De Van Eyck a Rubens. La senda española de los artistas flamencos en el Museo del Prado, Madrid, 2009, pp. 105-125. Algunas partes han sido resumidas y otras actualizadas con la más reciente bibliografía: P. COLMAN, Jan van Eyck et Jean sans Pitié, Bruselas, 2009; V. HERZNER, "Der Madrider Lebensbrunnen aus der Werkstatt Jan van Eycks und die zielsicheren Irrwege der Forschung”, Kunstgeschichte. Texte zur Diskussion, 2011-9 (http://www. kunstgeschichte-ejournal.net/discussion/2011/herzner o urn:nbn:de:0009-23-28428; última visita 8 mayo 2011); L. DEQUEKER, Het Mysterie van het Lam Gods. Filips de Goede en de Rechtvaardige Rechters van Van Eyck, Lovaina-París-Walpole, MA), 2011, particularmente pp. 73-83, 217-221; C. STROO (ed.), Preecykian panel paintings in the Low Countries, 2 vols, Bruselas, 2009.

2 La publicación más reciente sobre Van Eyck y su relación con el mundo mediterráneo es el catálogo de la exposición T. BORCHERT et alii, The Age of Van Eyck 1430-1450. The Mediterranean World and Early Netherlandish Painting (Brujas, Groeningemuseum), Gante, 2002. El mismo autor prepara una monografía (-Van Eyck, Complete Works-) que será publicada en breve. La crónica del viaje de la embajada borgoñona fue publicada íntegramente por W.H.J. WEALE, Hubert and John van Eyck. Their Life and Work, Londres-Nueva York, 1908, pp. lv-lxxii. Ha sido comentada por L. VAN PUYVELDE, "De reis van Jan van Eyck naar Portugal”, Koninklijke Vlaamse Academie voor Taal-en Letterkunde. Verslagen en Mededeelingen, enero (1940), pp. 17-27. Para un análisis de la crónica y de otros documentos sobre Jan van Eyck véase J. PAVIOT, "La vie de Jan van Eyck selon les documents écrits”, Revue des archéologies et historiens d'art de Louvain, XXIII (1990), pp. 83-93. 
Baudouin de Lannoy, consejero y chambelán, retratado por Jan Van Eyck (Berlín, Gemäldegalerie); el maestro Gilles d'Escornaix, doctor en Derecho; André de Toulongeon, caballerizo; el maestro Jean Hibert, secretario, varios empleados y servidores, y el pintor "Johannes de Eck". El encargo que este último llevaba consistía en retratar a la infanta portuguesa para que el duque se hiciera una idea del aspecto de su posible futura esposa.

La salida tuvo lugar el 19 de octubre de 1428 desde el pequeño puerto flamenco de Sluis. La delegación ducal partió en dos galeras venecianas en dirección a Sandwich, en Inglaterra. Tras hacer escala en Camber, Plymouth y Falmouth la flota salió finalmente el 2 de diciembre hacia España. Nueve días más tarde llegaron a Bayona, en Galicia, y el 18 de diciembre desembarcaron en el puerto de Lisboa. La delegación fue recibida en audiencia el 12 de enero de 1429 en la ciudad de Avis, donde negoció el matrimonio entre Felipe el Bueno e Isabel de Portugal. Durante las cuatro semanas que residió allí, Jan Van Eyck se dedicó a "paindre bien au vif la figure de ma dite dame l'infante Elizabeth" (pintar al natural la figura de mi señora la infanta Isabel). Desgraciadamente, el retrato de la infanta no se ha conservado. Hacia el 12 de febrero el borrador del compromiso fue enviado en dos ejemplares a Felipe el Bueno, uno por tierra y otro por mar. Podemos suponer que en ambos envíos se añadió un retrato de la infanta y que por lo tanto Van Eyck había realizado dos ejemplares del mismo. Pasaron casi cuatro meses antes de que se recibiera una respuesta de Felipe el Bueno. Los borgoñones aprovecharon el tiempo para explorar la Península Ibérica. Fueron a Santiago de Compostela, y visitaron, probablemente en Valladolid, al rey de Castilla, Juan II (1405-1454) y al Duque de Arjona, Don Fadrique (1388-1430), aunque éste también les pudo haber recibido en su residencia de Zamora. Fueron recibidos asimismo por el rey de Granada, Muhammad VIII (1409-1431). La crónica del viaje menciona la visita a otros señores en otras regiones y ciudades pero desgraciadamente no especifica cuáles.

A finales de mayo, los emisarios borgoñones se encuentran de nuevo en Lisboa, donde el contrato de matrimonio fue definitivamente formalizado el 11 de junio. El 24 lo registró un notario y al día siguiente el matrimonio por poderes fue solemnemente celebrado en la capilla del castillo de Lisboa donde Jean de Roubaix, jefe de la misión, actuó como sustituto del duque. A finales de septiembre, antes de embarcar a la nueva duquesa de Borgoña en una de las naves que la llevarían a Flandes, todavía se organizaron tres días de fiesta fastuosa. A causa del mal tiempo la flota sólo pudo salir desde Cascais el 17 de octubre. Tras hacer escala en Galicia, sólo pudieron comenzar la travesía a Inglaterra el 25 de noviembre. La galera de Jean de Roubaix fue la primera en llegar al puerto flamenco de Sluis, el 6 de diciembre; la de la duquesa llegó, según el manuscrito, el día de Navidad de 1429. En Sluis el matrimonio fue consagrado por los obispos de Tournai y de Évora. Después de su entrada triunfal en Brujas se organizaron bailes, banquetes y torneos. Hasta aquí el relato del cronista. 
La estancia de Jan van Eyck en la Península Ibérica duró por lo tanto casi diez meses, de los cuales apenas necesitó uno para retratar a la infanta Isabel. En la bibliografía reciente se advierte con razón del valor excesivo que se ha concedido a este viaje. Efectivamente, no se conocen documentos que atestigüen la realización de otras obras por Jan van Eyck durante este viaje, ni la recepción de encargos de España o Portugal. Sin embargo, tampoco debemos infravalorar la importancia de este viaje. Como observador minucioso que era, Jan Van Eyck debió sin duda quedarse impresionado por los nuevos paisajes, los trajes locales, las costumbres, los productos sureños y las lujosas fiestas de la corte de Portugal. Posiblemente el pintor llevara consigo un cuaderno de bocetos durante el viaje. La vegetación mediterránea, la arquitectura y los azulejos valencianos de sus pinturas pueden tener su origen en este cuaderno. Gracias a la delegación borgoñona, Jan van Eyck entró también en contacto con nobles portugueses, castellanos y aragoneses, cuyo aprecio por la pintura flamenca es bien conocido. También se ha de mencionar que, muy probablemente, Jan van Eyck conoció durante su estancia en Portugal a Lluís Dalmau (activo 1428-1461), pintor de corte de Alfonso V de Aragón (1396-1458). Dalmau formaba parte del séquito aragonés que acompañaba a Leonor de Aragón, prometida de Duarte de Portugal y cuya entrada triunfal en Lisboa se celebró fastuosamente a finales de mayo de 1428 . El encuentro entre los dos pintores tendrá influencias en el futuro. Dos años más tarde Lluís Dalmau fue enviado a los Países Bajos por su patrono, y allí fue recibido por Jan van Eyck en su taller. Van Eyck se encontraba en ese momento ocupado con la elaboración del Políptico del Cordero Místico y Lluís Dalmau copió, entre otras cosas, los ángeles, que al volver a Barcelona retomó en su Virgen de los Concellers (Barcelona, Museu Nacional d'Art de Catalunya).

\section{Una obra}

Sabemos que el Rey Enrique IV de Castilla (1425-1474), donó al recién fundado monasterio jerónimo de Santa María del Parral de Segovia "un retablo rico de pinsel de Flandes que tiene la ystoria de la dedicación de la iglesia", conocido ahora como La Fuente de la Vida . Esta obra es una de las escasas pinturas fla-

3 La bibliografía sobre La Fuente de la Vida es demasiado amplia para comentar de forma exhaustiva. Los estudios más significativos, citados en este artículo, son el importante artículo de P. DE MADRAZO, "El triunfo de la Iglesia sobre la Sinagoga, cuadro en tabla del siglo XV atribuido a Jan van Eyck", Museo español de Antigüedades, IV (1875), pp. 1-40; la tesis doctoral sobre la tabla de J. BRUYN, De levensbron. Het werk van een leerling van Jan van Eyck, Utrecht, 1957; la recensión de ésta por O. PÄCHT, "Rezension J. Bruyn, Van Eyck-problemen", Kunstchronik, 9 (1959), pp. 254-258; un amplio desarrollo de la tesis de Pächt por C. STERLING, "Jan van Eyck avant 1430”, Revue de l'Art, 33 (1976), pp. 34-37. Para las demás referencias sobre la Fuente de la Vida antes de 1980, véase la bibliografía exhaustiva en E. BERMEJO, Los Primitivos en España, vol. I, Madrid, 1980, p. 50. Entre las publicaciones que han visto la luz después de 1980, mencionamos el artículo poco conocido pero útil de J.K. STEPPE, "De echo van het 'Lam Gods' van de gebroeders van Eyck in Spanje", RAM-Rapport, 4 (1990), pp. 2-63. Una investigación detallada que complementa la tesis de Pächt es V. HERZNER, Jan van Eyck und der Genter Altar, Worms, 1995, pp. 
mencas que se encontraban en España desde fecha muy temprana, a saber entre 1459, año de la puesta en funcionamiento del convento, y 1474, en que falleció Enrique IV.

¿Podemos deducir de estos datos que Enrique IV es el comitente de la obra? ¿Hay elementos que indiquen que esta obra fue específicamente concebida para el claustro segoviano? ¿Qué elementos de la pintura son deudores de Jan van Eyck? ${ }^{4}$ Estas y otras preguntas han tenido en vilo a muchos historiadores del arte. Los primeros estudios datan de los años cincuenta del siglo XIX. Eruditos famosos como Carl Justi, Friedrich Winkler, Otto Pächt y Erwin Panofsky opinaron sobre el cuadro. En 1977 Enrique Lafuente Ferrari escribió que aún habrían de correr ríos de tinta sobre esta obra, y tenía razón, puesto que hasta hoy la obra sigue invitando a los historiadores del arte a formular las teorías más diversas. A pesar de los numerosos estudios, las opiniones acerca de la lectura correcta de esta obra son extraordinariamente dispares. Este artículo no pretende sobrecargar la pintura con una nueva e ingeniosa interpretación, sino confrontar las diferentes teorías existentes de forma concisa sin dejarnos llevar por opiniones atractivas pero poco sólidas.

La donación de la pintura al claustro segoviano aparece en el libro becerro, titulado Fundación del Parral (Biblioteca Nacional de España), que incluye una lista de los paramentos y obras de arte donados por Enrique IV. La referencia en el manuscrito al cuadro del Prado fue descubierta por Pedro de Madrazo en $1875^{5}$. Antes de esta fecha, se suponía que el panel del Prado procedía de la catedral de Palencia, donde Antonio Ponz había señalado a finales del siglo XVIII una pintura con exactamente la misma representación. Gracias a Madrazo sabemos que se trata de dos obras diferentes. El ejemplar de Palencia es una copia tardía que en 1813 fue confiscada por los franceses, que luego pasó por el

\footnotetext{
51-111. Para la atribución de la obra a un colaborador en el taller de Jan van Eyck véase S. JONES, "The Use of Workshop Drawings by Jan van Eyck and his Followers”, S. FOISTER, S. JONES y D. COOL (eds.) Investigating Jan van Eyck, Turnhout, 2000, pp. 197-207. Además de los autores ya citados, los estudios recientes que se concentran en la iconografía de La Fuente de la Vida son entre otros H. SCHLIE, Bilder des Corpus Christi. Sakrametaler Realismus von Jan van Eyck bis Hieronymus Bosch, Berlin, 2002, pp. 33-34; L.A. BLACKSBERG, "Between Salvation and Damnation. The Role of the Fountain in the Fountain of Life (Madrid: Museo del Prado)", B. BAERT y V. FRAETERS (eds.), Het Wellende Water. De bron in tekst en beeld in de middeleeuwse Nederlanden en het Rijnland, Lovaina, 2005, pp. 157-173.

4 Las especulaciones en torno al encargo y a los supuestos retratados fueron tratadas entre otros por P. POST, "Der Stifter des Lebensbrunnens der Van Eyck", Jahrbuch der preussischen Kunstsammlungen, 43 (1922), pp. 120-125; J. SIX, "De Orde van den Knoestigen Stok en van de Schaaf”, Mededelingen der Koninklijke Akademie van Wetenschappen, afdeling Letterkunde, LVIII (1924), pp. 53-70; F. WINKLER, "Die Stifter des Lebensbrunnens und andere Van-Eyck-Fragen”, Pantheon, VII (1931), pp. 188-192; C. PEMÁN Y PEMARTÍN, "Contribución al estudio de la iconografía de la 'Fuente de la Vida' eyckiana del Museo del Prado", Miscellanea Jozef Duverger. Bijdragen tot de Kunstgeschiedenis des Nederlanden, I (1968), pp. 66-82; y Juan van Eyck y España, Cádiz, 1969, pp. 70-99.

5 P. DE MADRAZO, "El triunfo de la Iglesia sobre la Sinagoga, cuadro en tabla del siglo XV atribuido a Jan van Eyck”, Museo español de Antigüedades, IV (1875), pp. 1-40.
} 


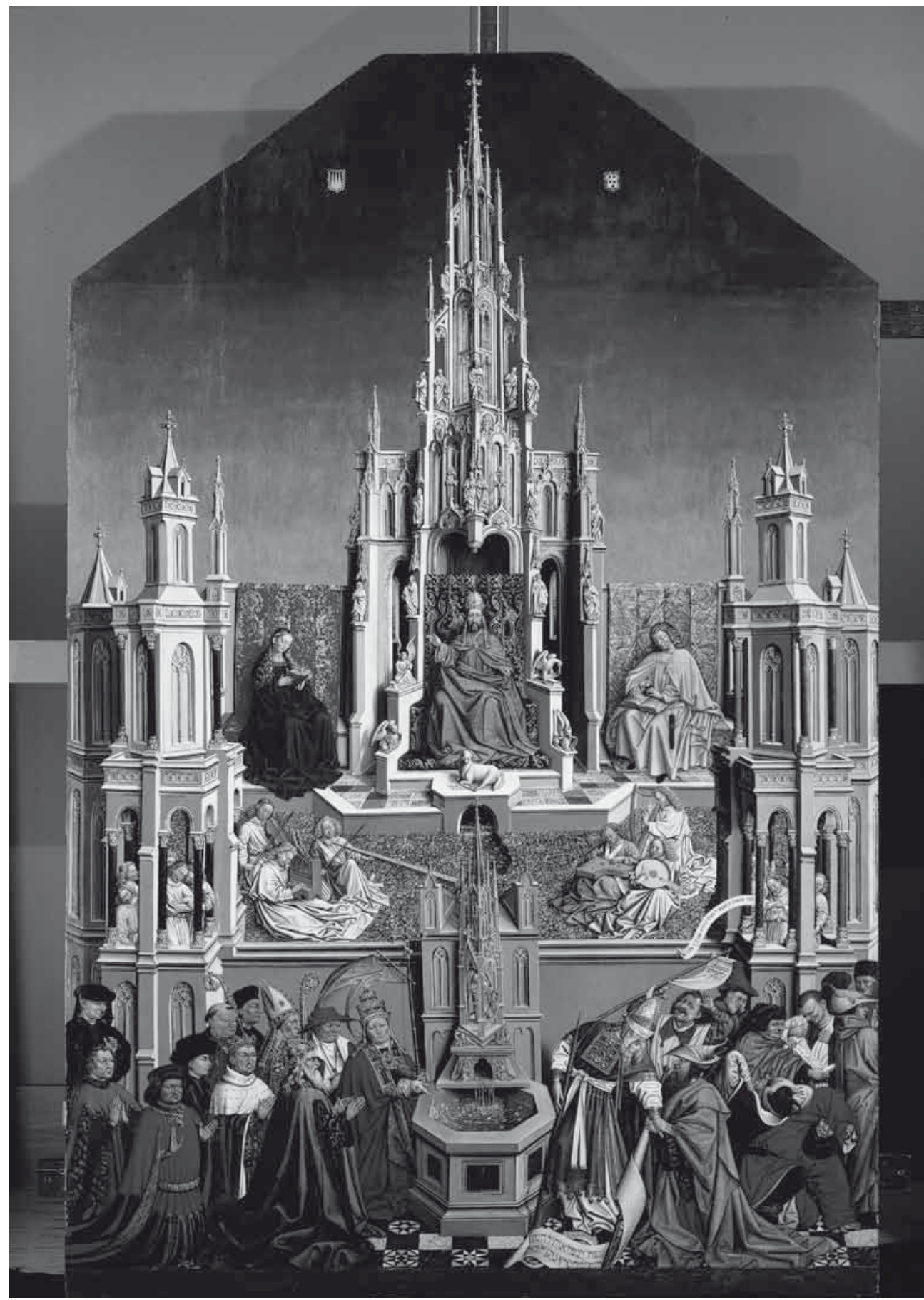

Fig. 2. Cristóbal de Velasco, La Fuente de la Vida, 1592 (Allen Memorial Art Museum, Oberlin, Ohio). 
mercado de arte parisino y que ahora está en el Allen Memorial Art Museum de Oberlin', en Ohio (fig. 2). La Fuente de la Vida del Prado es sin duda la obra donada por Enrique IV al claustro de El Parral $^{7}$ y que aparece en los inventarios de la desamortización de Mendizábal correspondiente al convento. La pintura pasó a continuación a la colección del Museo de la Trinidad, donde recibió el número de inventario 245. En 1872 llegó al Museo del Prado. Mientras el ejemplar del Prado es de "pinsel de Flandes" como consta en el libro becerro, la versión de Palencia es una copia española, realizada hacia 1592 por el pintor toledano Cristóbal de Velasco por encargo de don Pedro García de Loaysa de Girón, canónigo y más tarde arzobispo de Toledo. Las armas de éste último figuran en la parte superior de la tabla: a la izquierda Girón y a la derecha Loaysa. Una segunda copia (fig. 3), también española pero de calidad muy inferior a la minuciosa copia de Cristóbal de Velasco, y proce-

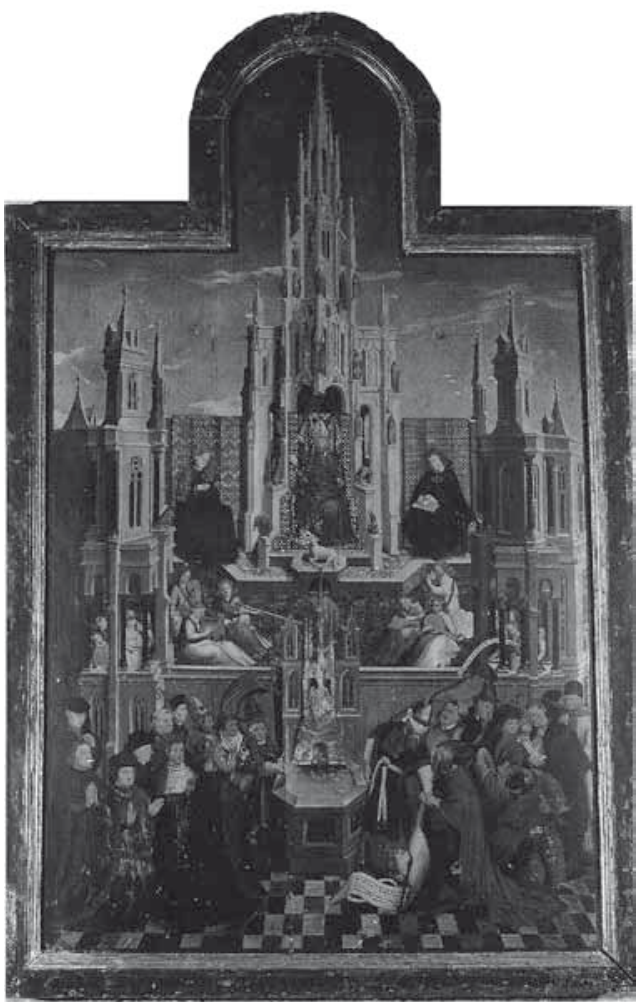

Fig. 3. Anónimo español, La Fuente de la Vida, 1560 (Museo Catedralicio, Segovia). dente de la Catedral de Segovia, se conserva en el museo catedralicio. La fecha de ejecución "1560" figura sobre el brocal de la fuente.

Volvemos ahora a centrarnos en la pintura flamenca en la que se basaron ambas copias españolas. El panel mide 181 por $119 \mathrm{~cm}$ y tiene un marco moderno. Basándonos en la radiografía de la tabla, en la que se aprecia un borde no pintado continuo, podemos deducir que la forma de la tabla actual se corresponde con la original, lo que algunas publicaciones anteriores contestaron. La pintura está estructurada arquitectónicamente en tres registros. En el registro superior domina una construcción gótica decorativa tipo tabernáculo en la que Cristo está sentado con un cordero a sus pies. El trono está decorado con esculturas de los símbolos de los

6 Sobre la copia española de La Fuente de la Vida en Oberlin véase F. COLLAR DE CÁCERES, "Una pintura, un pintor y un arzobispo. En torno a una copia de la Fuente de la Vida”, Estudios Segovianos XXXV, 91 (1994), pp. 757-776. También fue estudiada por J. BRUYN, “A puzzling picture at Oberlin: The Fountain of Life”, Allen Memorial Art Museum Bulletin, XVI, 1 (1958), pp. 5-19; y por J.K. STEPPE, op. cit., 1990.

7 Para la historia del Monasterio de El Parral véase I. MATEO et alii, "El Monasterio de Santa María del Parral (Segovia)", Boletín de la Real Academia de Bellas Artes de San Fernando, 84 (1997), pp. $155-182$. 
cuatro evangelistas. A la izquierda y a la derecha de Cristo se encuentran María y Juan Evangelista. Ella lee un libro, él escribe otro.

El segundo registro está ocupado por un jardín paradisiaco. Bajo el trono de Cristo se encuentra el nacimiento del río con el agua de la vida que arrastra hostias sagradas. A ambos lados se encuentran figuras femeninas con instrumentos musicales, que la literatura suele identificar con ángeles. A la izquierda, vemos tres ángeles tocando una trompeta marina, un órgano portátil y una viola de arco. A la derecha, tocan un arpa gótica, un laúd y un salterio. En cada una de las logias de los pequeños edificios laterales se encuentra media docena de ángeles.

Abajo, totalmente separado por un muro, se representa el nivel terrenal, donde el agua de la vida se recoge a través de un tabernáculo dorado en una fuente octogonal. A ambos lados se encuentra un grupo de once personas que representan el cristianismo y el judaísmo respectivamente. Entre los miembros del grupo de la izquierda reconocemos a un papa, señalando la fuente, un cardenal, un obispo, un emperador, y detrás de ellos un abad, un canónigo o presbítero y algunos ricos burgueses y nobles. El grupo de la derecha está encabezado por un sumo sacerdote judío, con los ojos vendados y con un estandarte roto en la mano. A su lado un hombre deja caer una filacteria. Los demás judíos dan muestras de desconsuelo y consternación ${ }^{8}$. Varias figuras se giran dando la espalda a la fuente. Uno se tapa las orejas, otro los ojos. En el centro hay uno que parece romper un texto enrollado que tiene en las manos. Las inscripciones en el estandarte, en los dos rollos y en los ropajes, contienen caracteres hebreos pero no son legibles. En toda la pintura sólo hay un texto legible. Figura en la filacteria que sujeta un ángel sobre los judíos y contiene el texto proveniente del Cantar de los Cantares (IV, 15): "can[ticum cantorum] 4. fons ortor[um,] pute[us] aquar[um] vivenci[um]" [Fuente de huertos, Pozo de aguas vivas].

La interpretación iconográfica del conjunto es muy compleja. Esta complejidad se refleja en los títulos que esta obra ha recibido a lo largo de su historia. Mientras que el libro becerro del siglo XV menciona la obra como La Dedicación de la Iglesia, los eruditos del siglo XIX se concentraron en la confrontación entre los cristianos y los judíos y decidieron que representaba El Triunfo de la Iglesia sobre la Sinagoga, un título que aparece recurrentemente en la bibliografía. Para muchos estudiosos del siglo XX, el asunto principal de la pintura no es la representación de la Iglesia y la Sinagoga, sino la fuente del centro, de la que fluye el agua con las hostias sagradas del trono de Cristo directamente, es decir, una representación

8 Particularmente sobre los judíos en el Políptico del Cordero Místico y en La Fuente de la Vida, véase L. DEQUEKER, "Jewish Symbolism in the Ghent Altarpiece of Jan van Eyck (1432)", J. MICHMAN y T. LEVIE (eds.), Dutch Jewish History: Proceedings of the Symposium on the History of the Jews in the Netherlands (Tel Aviv, 1982), Jerusalem, 1984, pp. 347-362. El mismo autor prepara una publicación sobre este tema: Het mysterie van het Lam Gods. De Rechtvaardige Rechters en het Duizendjarige Rijk, Lovaina (KUL, Faculteit Godgeleerdheid) (en prensa). Recientemente las inscripciones hebreas han sido analizadas de nuevo por J. PAVIOT, "Les inscriptions grecques et hébraïques dans les tableaux eyckiens", Revue belge d'archéologie et d'histoire de l'art, LXXV (2006), pp. 53-73. 


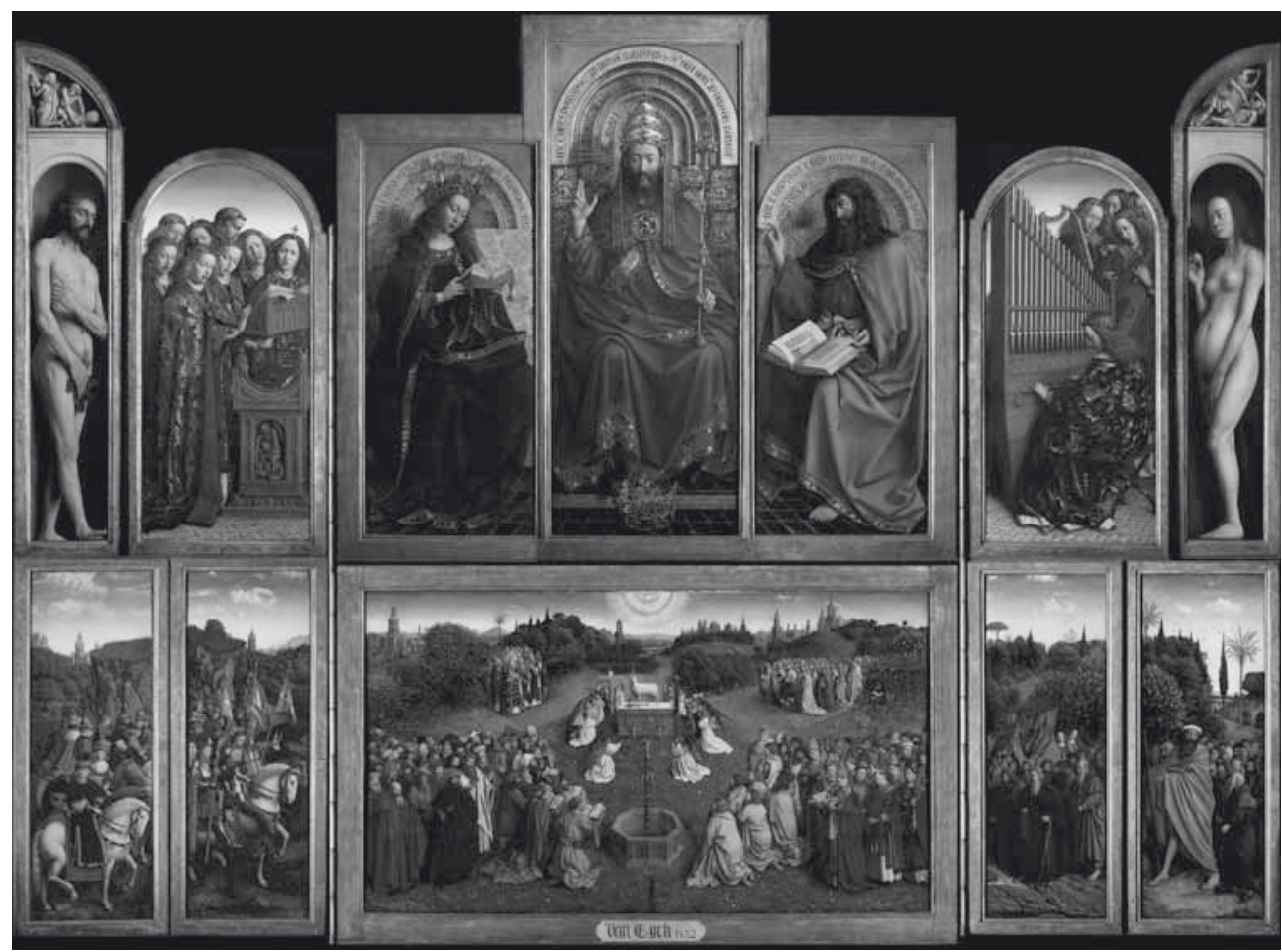

Fig. 4. Hermanos Van Eyck, El Políptico del Cordero Místico, 1432 (Catedral de San Bavón, Gante).

eucarística. Por ello y basándose en la inscripción latina, la obra recibió el título de La Fuente de la Vida, con el que hoy en día se conoce, aunque algunos autores no dejan de mencionar como subtítulo El triunfo de la Iglesia sobre la Sinagoga. Es curioso que nunca se haya vuelto a utilizar el título que la obra recibió en el mismo siglo XV, La Dedicación de la Iglesia. Volveremos más adelante sobre este tema.

Los primeros estudiosos de Van Eyck durante la segunda mitad del siglo XIX se sintieron intrigados por las llamativas coincidencias iconográficas y estilísticas entre la tabla del Prado y El Políptico del Cordero Místico de los hermanos Van Eyck (fig. 4). Las similitudes invitaron a algunos a atribuir La Fuente de la Vida a uno de los hermanos: Hubert o Jan. Sin embargo, la ejecución pictórica del panel madrileño y, en concreto, la utilización del color, el acabado de los rostros, de las ropas y de la vegetación, es de menor calidad que la de los dos maestros. En la bibliografía encontramos tres explicaciones.

La primera -Pächt ${ }^{9}$ y Herzner ${ }^{10}$ - considera que La Fuente de la Vida es una copia exacta del original perdido del mismo Van Eyck. La iconografía única y la

9 O. P̈̈CHT, op. cit., 1959.

10 V. HERZNER, op. cit., 1995. 
composición tan elaborada no puede ser, según Herzner, el resultado de un trabajo de compilación de un seguidor y ha de haber sido creada por el propio gran maestro Jan van Eyck. Herzner argumenta sólidamente que la obra original era de Jan Van Eyck y que tenía un destino en Flandes, y que la versión del Prado es una copia exacta realizada en Flandes y encargada por Enrique IV para el Monasterio del Parral.

En el estudio de copias exactas del siglo XV, suele ser la investigación técnica la que determina cuál es la obra original y cuál la copia. La tabla madrileña ha sido recientemente estudiada con radiografía y con reflectografía al infrarrojo ${ }^{11}$. Esta investigación ha sacado a la luz un dibujo preparatorio en el que se aprecian múltiples diferencias con el resultado final. El muro, por ejemplo, estaba provisto de una arcada ciega, y el ángel de la torre izquierda sostenía una filacteria. También los elementos arquitectónicos de las torres y algunos de los personajes cristianos muestran modificaciones. El artista hizo modificaciones respecto al proyecto original incluso durante la fase de ejecución pictórica. Todo esto indica que la pintura es el resultado de un proceso creativo y, por lo tanto, no se puede considerar como una copia exacta.

La segunda y más reciente explicación en la bibliografía la debemos a los defensores de la teoría de la copia que a base de los estudios técnicos se han visto obligado a reorientar sus ideas sobre La Fuente de la Vida. Herzner ${ }^{12}$ ahora acepta que no se puede tratar de una copia exacta y defiende que la pintura del Prado sea el original mismo, diseñado por Jan van Eyck, antes de la realización del políptico de Gante. Para explicar la calidad pictórica inferior comparada con la del suntuoso políptico, Herzner argumenta que probablemente el taller de Van Eyck llevó a cabo la pintura, quizás durante el viaje de su maestro a la Península Ibérica, es decir antes de la finalización por Van Eyck del políptico de Gante. Otro investigador tentado tanto por la autoría eyckiana como por una datación temprana, Pierre Colman, llegó a la conclusión de que el dibujo subyacente es sin duda de la mano de Jan y que la ejecución pictórica sería de su mejor alumno. Según él, la calidad de la pintura incluso ganaría si en una restauración se eliminaran todos los repintes.

La tercera y más difundida teoría ${ }^{13}$, relaciona la autoría de la tabla con el entorno próximo de Jan van Eyck, incluso con su taller a partir de los años 1430. La relación iconográfica con El Políptico del Cordero Místico es indiscutible. El

11 Los datos técnicos sobre la tabla del Prado fueron publicados por P. SILVA MAROTO, "Le dessin sous-jacent de deux peintures eyckiennes au Musée du Prado: Le Triomphe de l'Eglise sur la Synagogue, école de van Eyck, et Saint François recevant les stigmates, du Maître d'Hoogstraten", H. VEROUGSTRAETE y J. COUVERT (eds.), La peinture ancienne et ses procédés. Copies, répliques, pastiches (Colloque du dessin sous-jacent et de la technologie dans la peinture, 15, Bruges, 11-13 septiembre 2003), 2006, pp. 42-50.

12 V. HERZNER, op. cit., 2011-9.

13 J. BRUYN, op. cit., 1957; S. JONES, op. cit., 2000; y T. BORCHERT, op. cit., 2002. 
Políptico de Gante representa en la parte superior una Deesis en la que Cristo, vestido de rojo, está flanqueado por la Virgen María de azul y San Juan Bautista de verde. En La Fuente de la Vida San Juan Bautista ha sido sustituido por San Juan Evangelista. En el políptico se encuentran los ángeles músicos a ambos lados de la Deesis. El panel central del registro inferior (fig. 9) muestra al Cordero Místico sobre un altar, adorado por cuatro grupos: en la parte inferior, los representantes del Antiguo Testamento a la izquierda y los del Nuevo Testamento a la derecha; en la parte superior, una multitud de mártires masculinos a un lado y femeninos al otro. Algo más abajo se representa la fuente de la vida. Sobre el borde del pilón octogonal se lee: "Hic est fons aque vite procedens de sede Dei + Agni" (Apocalipsis, 22:1-2) ("Esta es la fuente del agua de la vida procedente del trono de Dios y del Cordero"), un texto que igualmente se podría poner en relación con la iconografía de la tabla del Prado.

La relación entre las dos obras no se limita a la iconografía. En algunos elementos concretos, queda patente que el autor de La Fuente de la Vida es deudor del gran maestro flamenco. Algunas figuras proceden directamente de Van Eyck, como la Virgen o Cristo. En ellas parece que el maestro siguió sobre todo los contornos de los modelos eyckianos, sin conseguir darles el mismo volumen que su maestro. El hecho de que el pintor tuviera acceso a modelos del taller de Van Eyck y que por lo tanto fuera un colaborador cercano, queda confirmado por la reciente investigación de Susan Jones ${ }^{14}$. Su estudio ha demostrado, entre otras cosas, que el suelo de azulejo del primer plano está realizado exactamente con los mismos patrones que utilizó Van Eyck en la tabla del Canciller Rolin y la Virgen (París, Musée du Louvre) (fig. 5). Incluso las medidas de los azulejos coinciden, lo que indica la utilización de una técnica mecánica de copiado. También los azulejos valencianos en la parte superior del cuadro proceden del taller de Jan van Eyck. En el políptico de Gante, el maestro utilizó azulejos parecidos, mientras que en La Virgen con Jan Vos y dos Santas (Nueva York, The Frick Collection) (fig. 6) los azulejos son idénticos.

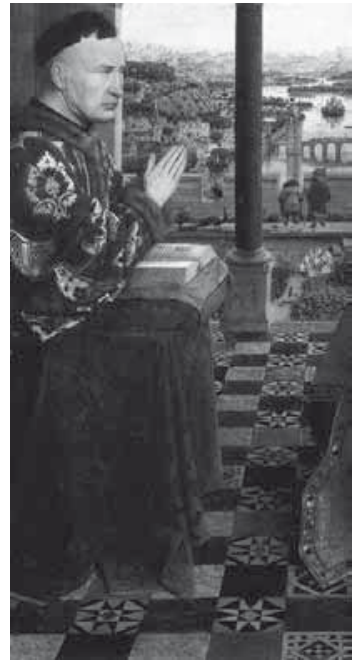

Fig. 5. Jan Van Eyck, Virgen del Canciller Rolin, detalle de los azulejos, 1434-1435 (Musée du Louvre, París). Este cuadro fue pintado entre 1441 y 1443 por un colaborador de Van Eyck que se sirvió generosamente de los modelos de su maestro, quien murió poco después de que la obra fuera encargada. Algunos autores han querido atribuir esta tabla y La Fuente de la Vida al mismo pintor ${ }^{15}$. Otros iden-

\footnotetext{
14 S. JONES, op. cit., 2000.

15 J. BRUYN, op. cit., 1957.
} 


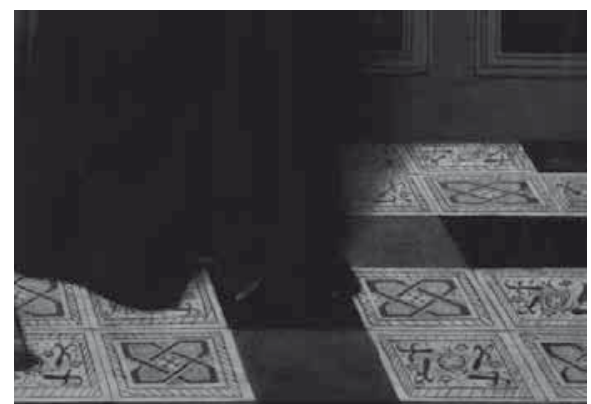

Fig. 6. Jan Van Eyck (colaborador), Virgen con Jan Vos y dos Santas, detalle de los azulejos, 1441-1443 (The Frick Collection, Nueva York).

tifican al maestro de La Fuente de la Vida con Petrus Christus ${ }^{16}$, a pesar de que éste no se instaló en Brujas hasta 1444, tres años después de la muerte de Van Eyck. Sin embargo, es llamativa la similitud del rostro de la Virgen del cuadro de Madrid con el de la Virgen de Christus conservado en Budapest (Szépmüveseti Muzeum). Otro parecido con Christus señalado por Jones es el uso del mismo patrón para el brocado en la obra de Madrid (detrás de San Juan) y para el de La Virgen y el Niño con los santos Jerónimo y Francisco (Frankfurt, Städelsches Kunstinstitut) de Petrus Christus. Desde hace poco, también se menciona a Lambert Van Eyck como posible autor ${ }^{17}$. Lambert era el hermano pequeño de Jan y fue quien, junto con Margarita, viuda de éste, dirigió el taller al menos durante diez años más tras la muerte de Jan. Es llamativo también que la familia de Jan van Eyck recibiera ayuda financiera del duque Felipe el Bueno tras su muerte. Las similitudes entre La Fuente de la Vida y la obra de los discípulos de Van Eyck han llevado a varios historiadores a suponer que La Fuente de la Vida es una obra de compilación de un colaborador o seguidor anónimo de Van Eyck.

Lo que sabemos con certeza es que la tabla fue donada por Enrique IV al Monasterio de El Parral, seguramente hacia 1459, con motivo de la puesta en funcionamiento del monasterio. Pero Enrique IV seguramente no fue el comitente de la obra. Las únicas indicaciones que nos ayudan a reconstruir la historia original de esta obra son el lugar de su creación, su datación y su iconografía.

Hoy en día no cabe duda de que la tabla fue creada en Flandes, aunque algunos autores, fascinados por el viaje de Van Eyck de 1428-1429, hayan pensado que la obra fue realizada en la Península Ibérica con ocasión del encuentro de Jan Van Eyck con el rey Juan II de Castilla. No sólo nos indican el origen flamenco la utilización de modelos del taller del Van Eyck y la mención "de pinsel de Flandes" en el libro becerro. También la investigación material lo confirma. El soporte es de roble proveniente del Báltico y cubierto por una preparación a base de call ${ }^{18}$, mientras que lo habitual en España era pintar sobre tablas de pino con una imprimación de yeso. La hipótesis, recientemente propuesta por Dequeker ${ }^{19}$, de que la pintura podría ser una obra de Luís Dalmau ( $i$ - 1460), ha de ser descartada.

\footnotetext{
16 L. BRAND PHILIP, The Ghent Altarpiece and the Art of Jan van Eyck, Princeton, 1971.

17 P. SILVA MAROTO, op. cit., 2006.

18 C. PEMÁN Y PEMARTÍN, op. cit., 1968 y 1969.

19 L. DEQUEKER, op. cit., 2011, particularmente pp. 73-83, 217-221.
} 
En cuanto a la datación de la obra, un estudio dendrocronológico del soporte ha podido determinar que la tabla sólo pudo haber sido pintada después de $1428^{20}$. Herzner y Colman ${ }^{21}$ cuestionan los cálculos de este análisis dendrocronológico y llegan a datar la obra respectivamente en los años veinte (en torno a 1428) y en 1424. Una datación temprana puede explicar según ellos la iconografía sencilla y el estilo más modesto comparado con el gran políptico de Gante. Pero formalmente La Fuente de la Vida tiene poco en común con las escasas pinturas flamencas de los años $1420^{22}$, salvo si la consideramos como una obra excepcional y revolucionaria. Además ya vimos que el autor de la tabla recopila múltiples elementos de Van Eyck, no solo del políptico de Gante, sino también de otras obras suyas y de su taller. También la iconografía antijudía parece, como Dequeker ha podido demostrar, más bien una reacción al mensaje del políptico de Gante que un estudio preparatorio. Volveremos más adelante sobre este tema.

Si tenemos en cuenta las conclusiones de los análisis dendrocronológicos, dos teorías siguen en vigor hoy en día en cuanto a la posible datación y el contexto histórico. En las investigaciones recientes muchos autores dan por sentado que la obra data de los años 1445-1455 $5^{23}$. La fecha de creación de la obra se aproxima tanto a la de la donación de Enrique IV al claustro segoviano que resulta tentador considerar al donante también comitente de la obra. Además el claustro segoviano es una fundación de Enrique IV y, a la vez, el lugar donde él quería ser enterrado. Distintos autores ya han sugerido que la obra ilustra la propaganda anti-judía de Enrique IV y que la iconografía podía estar inspirada en el tratado anti-judío Fortalicium Fidei de Alonso de Espina, confesor de Enrique IV, escrito a finales de los años cincuenta. Para Bruyn ${ }^{24}$ la donación estaría incluso relacionada con el milagro de una hostia sagrada, profanada por unos judíos, que había tenido lugar a principios de siglo en Segovia y que desencadenó la expropiación de la sinagoga local y su reconversión en iglesia del Corpus Cristi. La denominación de la pintura "la dedicación de la iglesia", haría referencia según Bruyn a la fundación de esta iglesia segoviana. Lo extraño es que la pintura no fuera donada a la Iglesia del Corpus Cristi. Además es cierto, como demostró Steppe ${ }^{25}$, que la denominación "dedicación de la iglesia" no alude a una iglesia como edificio sino a los orígenes

20 P. SILVA MAROTO, op. cit., 2006. Para una interpretación de los datos dendrocronológicos véase P. KLEIN, "Dendrochronological Findings of the van Eyck-Christus-Bouts Group", M.A. Ainsworth (ed.), Petrus Christus in Renaissance Bruges. An Interdisciplinary Approach, New York-Turnhout, 1995, pp. 149165.

21 P. COLMAN, op. cit., 2009; y V. HERZNER, op. cit., 2011-9.

22 C. STROO, op. cit., 2009.

23 S. JONES, op. cit., 2000; T. BORCHERT et alii, The Age of Van Eyck 1430-1450. The Mediterranean World and Early Netherlandish Painting (Brujas, Groeningemuseum), Gante, 2002; y L. DEQUEKER, op. cit., 2011.

24 J. BRUYN, op. cit., 1957.

25 J.K. STEPPE, op. cit., 1990. 
de la Santa Iglesia en su totalidad. Hoy en día el contexto histórico presentado por Bruyn no goza de mucho crédito, pero su datación en torno a 1455 sigue en vigor para muchos autores.

Basándose principalmente en criterios de orden iconográfico otros autores sitúan La Fuente de la Vida en los años $1430^{26}$. Si esta datación fuera la correcta, lo primero que habría que descartar es que la obra estuviera destinada al claustro segoviano, ya que los primeros pasos que conducen a su fundación sólo datan de 1447. A favor de una datación en los años treinta abogan, en primer lugar, las similitudes con el Cordero Místico de 1432 en cuanto a iconografía general y composición. Aunque la construcción arquitectónica en La Fuente de la Vida se ha relacionado en distintas ocasiones con una custodia española o con una torre sacramental flamenca, parece asimismo posible que esté inspirada en el baldaquino escultural que se encontraba originalmente sobre el Cordero Místico. La rígida estructura en tres planos aparece de forma muy semejante en la Biblia de Alba de 1430-1431, la primera traducción castellana de la Biblia hebrea, dedicada a Juan II de Castilla y realizada por el judío Rabí Mosé Arragel. Pächt ${ }^{27}$ supuso que el iluminador español se había inspirado en La Fuente de la Vida, y que por tanto la pintura data de antes 1430, pero esto parece poco probable. La inspiración en sentido contrario tampoco se explica fácilmente. En mi opinión, y de acuerdo con Isabel Mateo (1980), no hay una relación directa entre ambas representaciones.

Ha habido diversos intentos de reconstruir el contexto histórico del encargo a base de los supuestos retratos en el grupo de cristianos (fig. 7). Estos son tan individualizados y su dibujo subyacente es tan elaborado, que casi seguro representan o por lo menos intentan representar a personas de la época. De todas las distintas identificaciones propuestas en la bibliografía nos limitamos a las más serias. Nadie duda por ejemplo de que el emperador tenga muchas similitudes con los retratos conocidos de Segismundo de Luxemburgo, emperador de Alemania de 1411 hasta 1437, aunque sólo fue oficialmente coronado como emperador por el Papa en 1433. El Papa se identifica múltiples veces con Martin V, pero como Segismundo recibió la corona sólo en 1433, es probable que no se trate de Martin V, que murió a principios de 1431, sino de su sucesor Eugenio IV, que fue Papa de 1431 a 1447. Según la bibliografía, el rey no sería Enrique IV, sino su padre Juan II, rey de Castilla de 1406 a 1454. Algunos autores suponen que Juan II es el comitente ${ }^{28}$, pero eso parece poco probable. Dada su posición prominente, esta función parece más bien concedida a los tres hombres vestidos según la moda borgoñona a la izquierda. Ha habido mucha discusión en torno a su identificación. Los primeros estudiosos, basándose en los supuestos autorretratos de Jan y Hubert van Eyck en la tabla de los

\footnotetext{
26 C. PEMÁN Y PEMARTÍN, op. cit., 1968; y C. STERLING, op. cit., 1976.

27 O. PÄCHT, op. cit., 1959.

28 C. PEMÁN Y PEMARTÍN, op. cit., 1968; y C. STERLING, op. cit., 1976.
} 


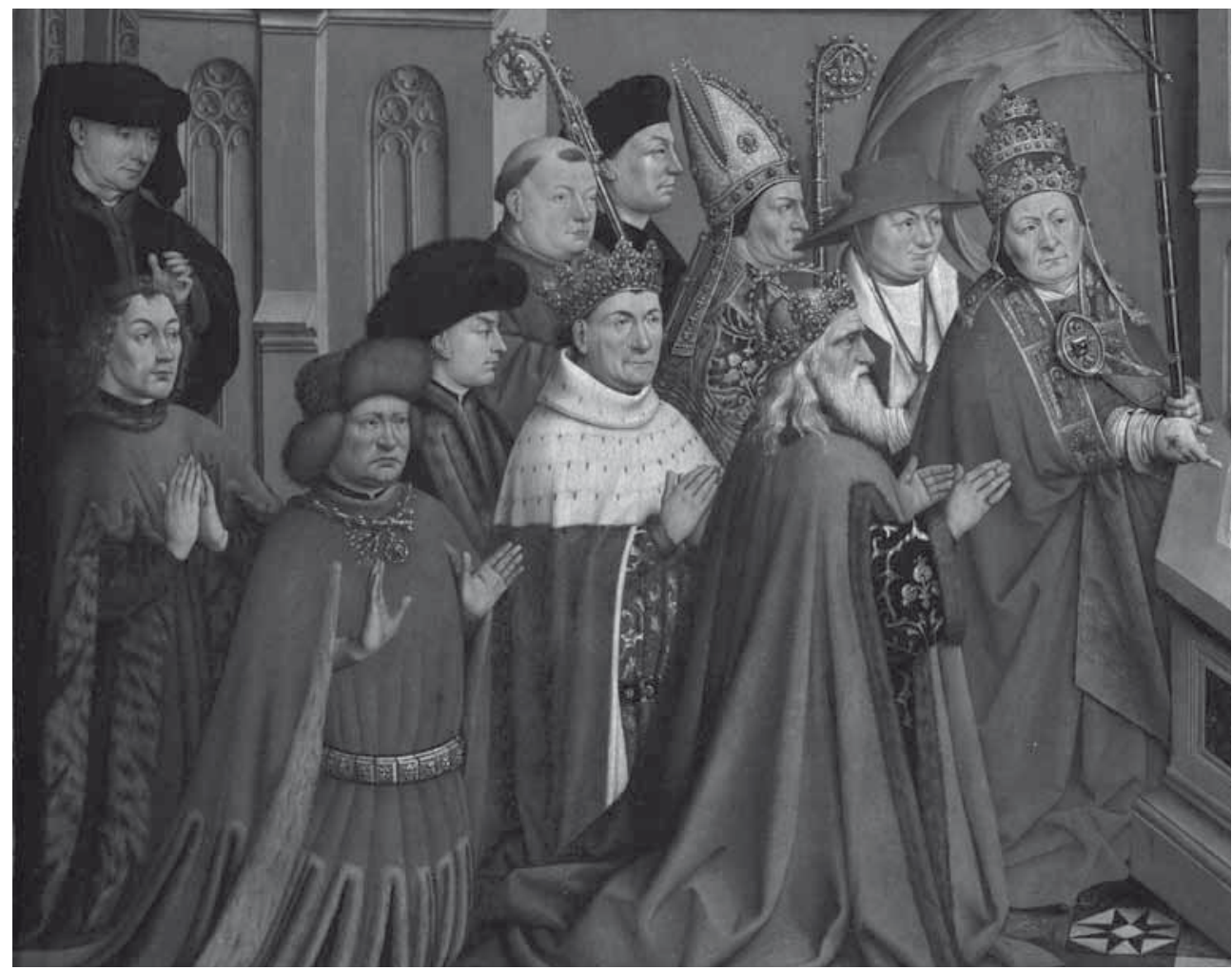

Fig. 7. Jan Van Eyck (taller), La Fuente de la Vida, detalle de los cristianos, h. 1435 (Museo del Prado, Madrid).

Jueces Justos del Cordero místico, han querido ver en el personaje en pie al propio Jan van Eyck y en la figura con el manto rojo a su hermano Hubert. El personaje de verde también procedería del políptico de Gante, concretamente de la tabla de los Caballeros de Cristo. Post ${ }^{29}$, sin embargo, identifica a los tres personajes con los duques de Borgoña Felipe el Temerario (1364-1404), Juan Sin Miedo (1404-1419)

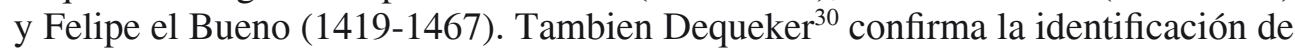
este último con Felipe le Bueno. Su traje negro además sería propio de los años $1430-40^{31}$ mientras que los vestidos rojo y verde, efectivamente, corresponden a la moda borgoñona anterior a 1420 , lo que podría indicar que se trata de retratos póstumos. El hombre que está en primer plano porta un llamativo signo en el cuello que alude a la orden del "bâton noueux" (bastón nudoso) ${ }^{32}$, una orden de caballería

\footnotetext{
29 P. POST, op. cit., 1922.

30 L. DEQUEKER, op. cit., 2011.

31 S. Jones op. cit., 2000.

32 J. SIX, op. cit., 1924.
} 
que tiene su origen en la casa de Orleans pero que desaparece en 1430 cuando Felipe el Bueno funda la orden del Toisón de Oro. De esta misma cabeza se conserva un retrato en Berlín (Gemäldegalerie), aunque el personaje representado tampoco ha sido identificado ${ }^{33}$. Entre los autores que relacionan La Fuente de la Vida con el viaje de Van Eyck a Portugal y España, César Pemán ${ }^{34}$ llega hasta considerar a los tres personajes como miembros de la embajada ducal, encabezada por Jehan de Roubaix, que sería el hombre vestido de rojo. Identifica a Jan van Eyck con el hombre que está de pie al fondo. Tambien Colman $^{35}$ ve en este personaje un autorretrato de Van Eyck. Muchas de las individualizaciones propuestas son difícilmente comprobables por falta de retratos seguros. Cuando uno supone que los retratados representan a personas contemporáneas a la creación del cuadro, es muy tentador deducir que la combinación de los representados lleva a los años de 1433 a 1437 , posible fecha del cuadro, que corresponde con el resultado dendrocronológico. Sin embargo, no se puede olvidar que, aparte de los hombres borgoñones, los representantes de la Santa Iglesia pueden proceder, como indica Bruyn ${ }^{36}$, de sus efigies difundidas sin que el pintor realmente quisiera referirse a ellos.

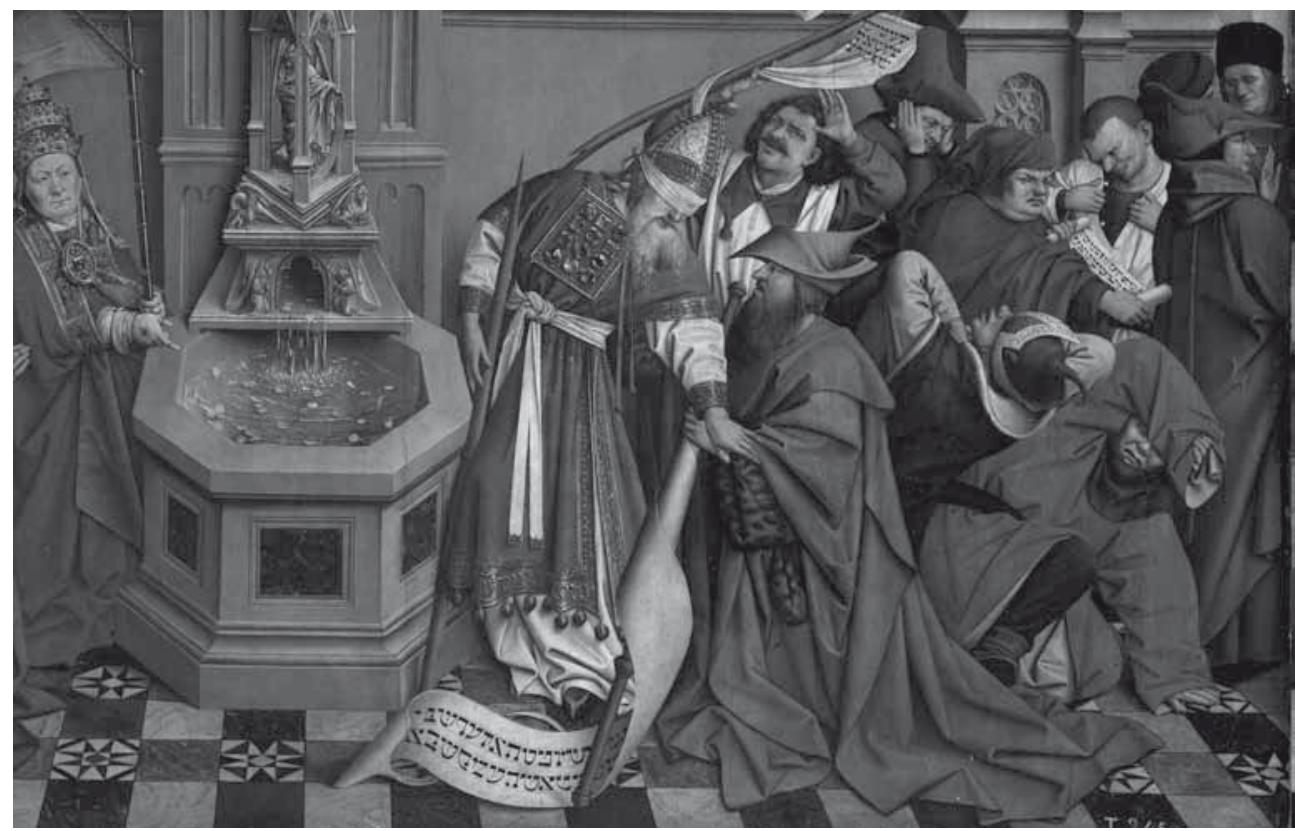

Fig. 8. Jan Van Eyck (taller), La Fuente de la Vida, detalle de los judíos, h. 1435 (Museo del Prado, Madrid).

\footnotetext{
${ }_{33}$ F. WINKLER, op. cit., 1931.

${ }^{34}$ C. PEMÁN Y PEMARTÍN, op. cit., 1969.

${ }^{35}$ P. COLMAN, op. cit., 2009.

36 J. BRUYN, op. cit., 1957.
} 
La atención que merece el grupo de la izquierda en relación con la identificación de los representados, contrasta sorprendentemente con la poca atención que en la bibliografía se concede al grupo de la derecha (fig. 8). Los personajes no son probablemente ningún retrato concreto, sino que representan a un grupo anónimo de judíos y a un sumo sacerdote. En el arte de los Países Bajos meridionales tal representación de un grupo de judíos es muy poco habitual. Del periodo anterior a Van Eyck sólo se conocen dos ejemplos alemanes de hacia 1420 que representan a un grupo de judíos de una forma muy similar: la tablita con la representación de la Cruz Viviente flanqueada por cristianos a un lado y judíos al otro (Chicago, Art Institute), y un dibujo que debió servir de boceto para una composición semejante (Leipzig, Museum der bildenden Künste). Hasta hace muy poco tiempo, el origen de la inspiración del pintor para el sumo sacerdote judío era incierto. Recientemente, Pereda ${ }^{37}$ ha podido demostrar que éste podría provenir de las Postillae, comentarios de la Biblia de Nicolás de Lyra, escritos en París entre 1322 y 1331, copiados y ampliamente difundidos por Europa.

La oposición entre Iglesia y Sinagoga enlaza de alguna manera con la iconografía tradicional en la que ambas se personifican en una mujer, la Iglesia triunfante y la Sinagoga con los ojos vendados. Para los cristianos la llegada y el sacrificio de Cristo significaban el cumplimiento de las profecías del Antiguo Testamento. Los judíos, sin embargo, no reconocían el Nuevo Testamento y por lo tanto eran considerados por los cristianos "ciegos" para la redención de Cristo. Esta controversia alcanzó su punto culminante en el arte y la literatura con la devoción al Santo Sacramento. Para la comunidad cristiana, la Eucaristía era el sacramento por excelencia, y se consideraba que los judíos la menospreciaban, ridiculizaban y profanaban. A finales del siglo XIV y a lo largo del XV creció la enemistad hacia los judíos y surgieron en los Países Bajos, así como en España, todo tipo de leyendas sobre hostias robadas y profanadas por judíos, que a la postre resultaban milagrosas. Lo que no es leyenda es que los judíos fueron condenados o forzados a convertirse al cristianismo por estos motivos.

Sin embargo, no todos los autores consideran La Fuente de la Vida necesariamente como un alegato anti-judío. Herzner ${ }^{38}$, por ejemplo, insiste en la concordantia veteris et novi testamenti, un principio que efectivamente era muy corriente en el arte y según el cual todos los hechos del Antiguo Testamento son simplemente una prefiguración de los del Nuevo. Herzner por lo tanto considera que la obra no era anti-judía y menos aún una alusión al anti-judaísmo español. Las inscripciones

37 F. PEREDA, Las imágenes de la discordia. Política y poética de la imagen sagrada en la España del 400, Madrid, 2007, pp. 109-114. El autor presentó la conferencia "From literal to spiritual reading. Reflections on Van Eyck's Fountain of Life" (rencontre GEMCA, Dire, penser et éprouver l'image entre théologie, rhétorique et esthétique durant la première modernité), en Louvain-la-Neuve, 18-20 de septiembre, 2008 y publicará en breve "Ojos que no ven, oídos que no oyen. Sentido literal y visión espiritual en la 'fuente de la vida"”, R. SÁNCHEZ AMEIJEIRAS (ed.), Gótico en frontera (en prensa).

38 V. HERZNER, op. cit., 1995. 
ilegibles en hebreo serían la prueba, según el autor, de que la obra estaba destinada a un público flamenco que no estaba familiarizado con el hebreo. Pereda ${ }^{39}$ ha desmentido recientemente esta lectura, y ha demostrado que las inscripciones ilegibles en hebreo son propias de las representaciones medievales de judíos en el norte de Europa y símbolo de la ceguera del judaísmo hacia los Evangelios.

En La Fuente de la Vida no podemos deshacernos de la impresión de que los judíos están representados de una forma extremadamente negativa. Mientras que el Papa señala ostensiblemente hacia las hostias en el agua, los judíos apartan la mirada. El estandarte del sumo sacerdote está roto. Un judío desgarra el texto enrollado. Otro se rasga las vestiduras. Las connotaciones negativas están presentes también en su posición a la derecha, que es la izquierda de Dios, y en el uso del amarillo en su vestimenta, un color que en la Edad Media era símbolo de odio y enemistad. Con esta representación resulta poco probable que la tabla sirviera como un manifiesto a favor de la conversión de los judíos, tal como lo propone Colman ${ }^{40}$.

Dequeker ${ }^{41}$ ha señalado que los judíos y los profetas en El Políptico del Cordero Místico (fig. 9) están representados de una forma totalmente distinta, incluidos en armonía en la gran comunidad de todos los santos, en adoración del Cordero Místico y a la izquierda, que es la derecha divina. En El Políptico de Gante no hay

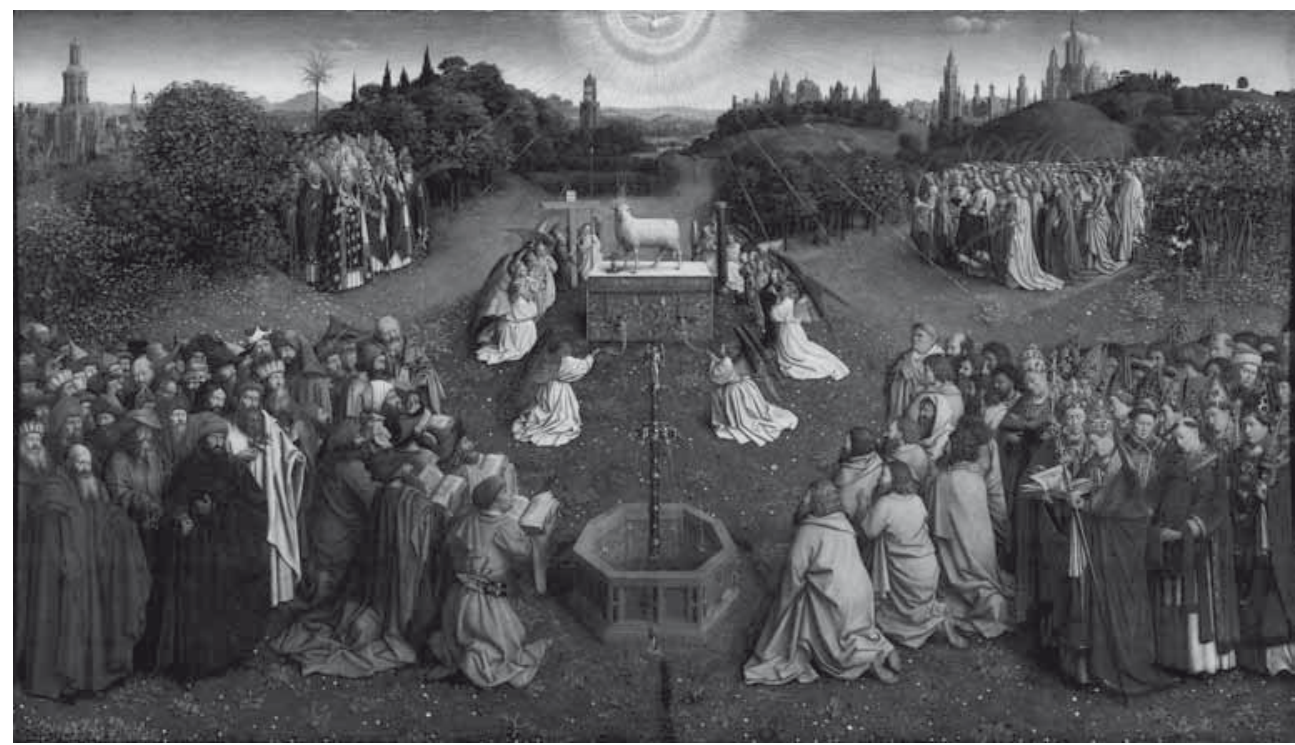

Fig. 9. Hermanos Van Eyck, Políptico del Cordero Místico, tabla central de la Adoración del Cordero Místico (Catedral de San Bavón, Gante).

39 F. PEREDA, op. cit., 2008.

40 P. COLMAN, op. cit., 2009.

${ }^{41}$ L. DEQUEKER, op. cit., 1984; у op. cit., 2011. 
ninguna oposición entre judíos y cristianos. Los judíos serían, según Dequeker, conversos, y la iconografía global del políptico haría referencia a la llegada del reino de los mil años, a la paz universal, al final del cisma de occidente y a la liberación de la Tierra Santa. Dequeker defiende con razón que la cargada iconografía del políptico de Gante supera el contexto devocional de la capilla Vijd y corresponde más bien a los ideales políticos y eclesiásticos de la corte de Felipe el Bueno.

Mientras Herzner ${ }^{42}$ considera el Políptico como una mera variación de La Fuente de la Vida, Dequeker ${ }^{43}$ la considera como una reacción totalmente opuesta al contenido del Políptico. Las diferencias entre uno y otro no se limitan a la representación de los judíos. Toda alusión al Apocalipsis desaparece en la tabla del Prado, que se centra en la Eucaristía. Por este motivo, por ejemplo, San Juan Bautista fue sustituido por San Juan Evangelista.

Las diferencias fundamentales entre El Cordero Místico y La Fuente de la Vida, se explican, según Dequeker, por la actitud más severa adoptada hacia los judíos en toda Europa, entre otras cosas, como consecuencia del decreto sobre los judíos y los conversos emitido en 1434 por el Concilio de Basilea. Sobre todo en España, en los años 1430 bajo Juan II, los judíos fueron privados de numerosas libertades y a menudo eran víctimas de multitudes excitadas y jueces cegados. Parece posible que La Fuente de la Vida encontrara su camino a España en este contexto.

Llama la atención que Cristóbal de Velasco en su copia de 1592 sustituyera las inscripciones ilegibles por textos hebreos legibles. Los textos, provenientes de los Salmos, no son relevantes para la iconografía de La Fuente de la Vida. El otro copista español que realizó en 1560 su versión para la catedral de Segovia tenía quizá menos talento artístico que Cristóbal de Velasco pero copió fielmente los textos hebreos ilegibles. Además añadió al marco de su copia dos inscripciones en latín que muy probablemente también decoraban el marco de la obra de El Parral. Bajo el grupo de cristianos se lee "Aput te est fons vite" y bajo el de judíos "Dereli $[n]$ querunt fonten aque vive". La primera cita proviene de los Salmos (36,9). En ella Dios es alabado con las palabras: "Porque en ti está la fuente de la vida, y en tu luz podemos ver la luz”. El segundo texto viene de Jeremías (2,13). En él Yahvé dice: "dos males ha hecho mi pueblo: me dejaron a mí, fuente de agua viva, y cavaron para sí cisternas, cisternas rotas que no retienen agua". Ambas inscripciones reflejan la oposición entre la Iglesia y la Sinagoga y parecen confirmar que La Fuente de la Vida en su contexto original debía de contener un mensaje claramente anti-judío.

Parece ser que el motivo por el que Enrique IV regaló este cuadro al Monasterio de El Parral no fue tanto el mensaje anti-judío, sino el tema de la fuente de la vida. En medio de la seca Castilla el claustro era como un oasis, conocido por su provisión de agua y sus jardines paradisíacos. En este contexto parece explicable que la

\footnotetext{
42 V. HERZNER, op. cit., 2011-9.

43 L. DEQUEKER, op. cit., 2011.
} 


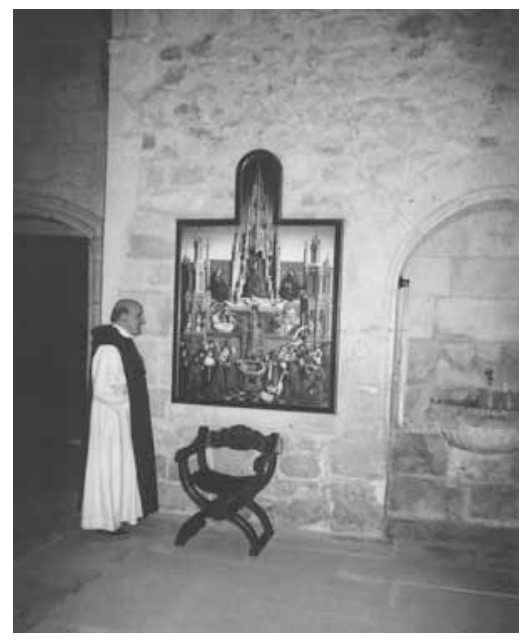

Fig. 10. Luk Dequeker, Fotografía del interior de la sacristía del convento de Santa María del Parral (Segovia) con una reproducción de La Fuente de la Vida. pintura no se colgara en la iglesia, sino en la sacristía (fig. 10), junto a la pila litúrgica donde los sacerdotes se lavaban las manos. Al ser copiada la obra en el siglo XVI se copió también su función. Así, la copia de la Catedral de Segovia estaba en la sacristía y el ejemplar de Cristóbal de Velasco se encontraba en la Catedral de Palencia al lado de la capilla de San Jerónimo, en una recapilla junto a la pila litúrgica.

Parece poco probable que el contexto del Monasterio de El Parral sea el original. La iconografía única, con un mensaje claramente antijudío y la representación de los líderes políticos y eclesiásticos de la Europa de los años 1430 hace suponer que La Fuente de la Vida fuera creada por encargo por un colaborador próximo a Van Eyck poco después del Políptico de Gante. Su primer destino era posiblemente la colección real de Juan II y el hijo de éste consideró la iconografía adecuada para donarla al Monasterio de El Parral, donde quería ser enterrado. Sigue siendo incierto si el comentado viaje de Van Eyck y el encuentro con Juan II en Valladolid pueden tener algo que ver con esta pintura. Asimismo, todavía queda sin aclarar de forma convincente cuál era el motivo exacto del encargo y quién era el comitente. 